\begin{tabular}{c|c}
\multirow{2}{*}{ EESD'15 } & The $7^{\text {th }}$ International Conference on Engineering Education for Sustainable Development \\
\cline { 2 - 2 } & Vancouver, Canada, June 9 to 12, 2015
\end{tabular}

\title{
EMBEDDING SUSTAINABILITY PRINCIPLES INTO ENGINEERING EDUCATION
}

\author{
Danielle Salvatore ${ }^{1,2}$, Naoko Ellis ${ }^{1}$, Susan Nesbit ${ }^{1}$, and Peter Ostafichuk ${ }^{1}$ \\ ${ }_{1}^{1}$ University of British Columbia, Canada \\ 2 dsalvatore@chbe.ubc.ca
}

\begin{abstract}
Because sustainability learning is necessarily situated in local culture and "place," engaging key communities-of-interest in planning and deployment is foundational to sustainability effort. Recently, the University Sustainability Initiative (USI), at the University of British Columbia (UBC), employed engagement techniques that reached out across the university campus to develop generic descriptions of sustainability attributes of graduating students, which propose that UBC students within all disciplines strive to develop four attributes in preparation for facing today's challenges (i.e., holism, sustainability knowledge, awareness \& integration, and acting for positive change) (1). The USI recognizes, "that in order to find creative solutions to the ecological, economic and social challenges of our time, we must explore, advance and apply our understanding of sustainability" (2).

This paper reports on a second set of engagement processes focused on developing the first stage of EESD degree-level learning outcomes that, in turn, aim to guide course redevelopment within the engineering programs. We start by presenting examples of sustainability learning opportunities offered in undergraduate programs elsewhere in North America. Most of these opportunities involve adding several courses to an already course-heavy degree. At several schools there is an option to complete a "certificate program" encompassing a few extra courses, but these certificate programs are not necessarily directed at engineering students. We then describe Applied Science Faculty engagement activities, aimed at measuring the interest of administrators, faculty members, staff, and students regarding incorporating sustainability learning opportunities within the common first year curriculum. We next relate informal first year student survey responses to the literature and we outline recommendations for advancing the development of sustainability learning within the first year curriculum.
\end{abstract}

\section{INTRODUCTION}

\subsection{Sustainability Learning Support at the University of British Columbia}

UBC's University Sustainability Initiative (USI), established in 2010, aims to support student development of the UBC Sustainability Attributes and, where possible, integrate sustainability teaching and learning, research, and operations. The USI Teaching and Learning Office coordinates a number of different programs to support sustainability teaching and learning, including the:

- maintenance of an inventory with over 500 courses where students learn about aspects of sustainability;

- SEEDS (Social, Ecological, Economic Development Studies) Program that provides students with on-campus, for-credit, learning experiences during which students work with university staff on projects in support of transforming UBC's campus into a sustainability hub (5);

- Greenest City Scholars Program where graduate students work for 250 hours with the City of Vancouver on a project aimed at helping the city achieve its Greenest City 2020 Action Plan (6); 
- Spotlight Program where selected instructors are awarded funds to improve the teaching and learning of sustainability within their course (7); and

- Sustainability Teaching Fellows program where selected faculty members work together on sustainability teaching projects that vary from year to year (8).

An outcome of the teaching fellows program is the UBC sustainability attributes (1) which propose that students graduate with four sustainability attributes, namely "holism," "sustainability knowledge," "awareness \& integration," and "acting for positive change" related to sustainability background.

The 2014-2015 cohort of Sustainability Teaching Fellows are charged with creating sustainability learning pathways in their respective faculties. A sustainability learning pathway is a collection of sustainabilityoriented courses that students pursue alongside their disciplinary focus. The Fellows meet periodically to share strategies, compare progress, and provide feedback.

\subsection{Sustainability Learning Pathway Initiative in the Faculty of Applied Science}

The Faculty of Applied Science (APSC) at UBC includes the School of Architecture and Landscape Architecture (SALA), the School of Community and Regional Planning (SCARP), the School of Nursing, six departments of engineering located at the Vancouver campus, and School of Engineering at the Kelowna campus. As members of the 2014-2015 USI Teaching Fellows cohort, two of the authors of this paper are supported by the USI for two years to initiate and develop sustainability learning pathways within the faculty.

The objectives of the APSC Sustainability Pathway Engagement Initiative are to:

- $\quad$ assess the interest and support by students and faculty members for sustainability learning pathways in APSC;

- develop sustainability pathway learning outcomes;

- $\quad$ build strategies for implementing undergraduate (UG) curriculum changes; and

- $\quad$ build strategies for creating pathways at the graduate $(G)$ levels.

This paper focuses on the assessment of interest and support for sustainability learning within the APSC community at UBC, particularly within the engineering communities related to the undergraduate curriculum. It then presents and analyzes informal survey and roundtable discussion data indicating gaps and misconceptions of engineering-for-sustainability knowledge, skills, and attitudes.

\section{PRECEDENT PROGRAMS AND LITERATURE REVIEWS}

This section includes a review of the engineering for sustainability programs available in North America and a literature review of program-level learning outcomes relevant to engineering for sustainability.

\subsection{Engineering for Sustainability Programs in North America}

Engineering undergraduate programs from eleven prominent engineering schools from across North America were examined with respect to their sustainability curricula. A summary of the schools is represented in Table 1. From the programs that were sampled, there were few formal sustainability pathways in engineering education, and half of the schools did not offer any type of pathway in sustainability. Those offering pathways, did so as add-ons, with additional courses required to achieve the pathway. At two schools there is an option to complete a "certificate program" encompassing a small number of extra courses, but these certificate programs were not necessarily directed at engineering students.

The University of Toronto "Sustainability Energy" minor, offered to all undergraduate engineering students, illustrates one possible pathway. Students are required to take six 1-semester courses, in addition to the standard engineering program requirements. The University of Toronto also offers an undergraduate engineering certificate program in Renewable Resources. The requirements for the certificate program include a minimum of 31 -semester courses from a select list. Both the minor and the certificate appear on student transcripts upon completion. 
Table 1: Summary of sustainability pathways in engineering programs across North America

\begin{tabular}{|c|c|c|c|c|}
\hline & School of Engineering & Pathway & $\begin{array}{l}\text { Additional } \\
\text { Courses? }\end{array}$ & Certificate Offered \\
\hline \multirow[t]{8}{*}{ Canada } & University of Toronto & Minor & Yes & Renewable Resources \\
\hline & Dalhousie University & - & - & $\begin{array}{l}\text { Sustainability } \\
\text { Leadership* }\end{array}$ \\
\hline & McGill University & Minor & Yes & \\
\hline & Queen's University & - & - & \\
\hline & University of Calgary & Specialization & Yes & \\
\hline & University of Manitoba & Specialization & - & \\
\hline & McMaster University & - & - & \\
\hline & Stanford University & Specialization & - & \\
\hline \multirow[t]{3}{*}{$\begin{array}{l}\text { United } \\
\text { States }\end{array}$} & $\begin{array}{l}\text { Massachusetts Institute of } \\
\text { Technology }\end{array}$ & - & - & \\
\hline & University of California at Berkeley & - & - & \\
\hline & Georgia Institute of Technology & Minor & Yes & \\
\hline
\end{tabular}

${ }^{*}$ Offered for all students, not just engineering students

This review indicates that very few engineering schools offer pathways in sustainability, possibly owing to the heavy course load for meeting the Canadian Engineering Accreditation Board (CEAB) or American Board for Engineering and Technology (ABET) criteria.

\subsection{Literature Review of Sustainable Education in Undergraduate Engineering}

The literature relevant to incorporating sustainability education in engineering can be divided into three main research questions:

- What is the level of knowledge and understanding of undergraduate engineering students in sustainability?

- Where are the gaps in sustainable education at an undergraduate level?

- What is the best method of implementing sustainable education into undergraduate curricula?

Researchers in Australia (9), Europe (10), and Ireland (11) have collected survey data from senior undergraduate engineering students in order to assess the level and gap in knowledge through sustainability education in undergraduate engineering students. Although these studies were done in various parts of the world, all three reveal similar phenomena. They report that the students' understanding of sustainable development was very broad, with meagre or no understanding of the complexity of the concepts. The majority of the student responses to survey questions demonstrate a lack of understanding regarding what sustainability is, or vagueness in understanding the concept. Further, the studies suggest that engineering students tend to connect sustainable development with environmental issues and neglect the other two pillars, economic and social issues. Results underline significant knowledge gaps regarding key social issues, as well as legislation, policy and standards. These studies also identified significant gaps in sustainable development in the engineering curriculum.

A study by Hanning et al. (12) indicate there is a range in sustainability knowledge across engineering disciplines, where certain disciplines such as engineering physics and computer science engineering do not view the relevance of sustainability to engineering to the same degree as chemical engineering. This study suggests there is a lack of knowledge of how some types of engineering work is related to sustainable development, meaning there may be a potential lack of integration of sustainability in engineering within some engineering courses. The study by Azapagic \& Shallcross (10) indicates that many engineering students regard sustainability more as a professional rather than a personal importance. Students also view sustainability as more important for future generations. The researchers 
conclude that sustainable development needs to become an integral part of engineering education programmes. They propose a three-tiered approach (10):

1. Dedicated lectures and tutorials on sustainable development;

2. Specific case studies; and

3. Integration of sustainability into the overall curriculum.

This idea of a tiered approach is also suggested by Burian (13), where sustainability is integrated into a civil engineering curriculum. Freshman and sophomore courses provide an introduction/description to sustainability and sustainable design; whereas, junior and senior technical courses and the capstone design project really incorporate sustainability with clear modules and examples. Their survey results show a clear increase in sustainability knowledge as the students progressed through the curriculum, that activities and assignments allowed them to achieve a deeper understanding and, finally, that the incorporation of multi-disciplinary interaction really enabled sustainable design practices.

\section{QUESTIONS AND METHODOLOGY}

The questions driving the Sustainability Learning Pathway (SLP) Initiative in APSC at UBC are aimed at gauging community interest in, and ideas about, sustainability curriculum development, and learning something about first year student understanding and misconceptions of engineering-for-sustainability.

Two questions guide the SLP Initiative:

1. Is there an interest in, and at what level do students, faculty members, and the Dean of the Faculty support the development of a sustainability learning pathway in the undergraduate engineering programs at UBC?

2. What are the knowledge gaps and misconceptions relating to sustainability of current first year students and how can this information aid in the design of appropriate sustainability learning outcomes for a common first year design course offered at UBC?

\subsection{Methodological Approach}

The questions described above are answered by the following actions:

- Meet with the Dean to discuss his support of the development of a sustainability learning pathway for engineering students and identify indicators of faculty member interest in sustainability learning within engineering programs.

- Develop and deploy an informal survey to first year engineering students aimed at measuring comprehension, experiences and attitudes towards sustainability.

- Convene a roundtable discussion with interested faculty members from across engineering departments to discuss possible sustainability learning outcomes at both the first and fourth year levels.

\subsubsection{Identifying Indicators of Faculty Interest in Sustainability Learning.}

Two of the authors conducted an informal meeting with the Dean on the subject of the APSC Sustainability Learning Pathway Initiative. No questions or agenda was set. The discussion was free ranging and candid.

One indicator was informally identified by the authors:

a) The Teaching and Learning Office of the University Sustainability Office take an annual inventory of UBC courses offering sustainability-related learning. The inventory is voluntary, that is, a general call to register courses is distributed to instructors across the university. Instructors must respond to this call in order for their courses to be listed in the inventory. The number of engineering courses in the inventory was identified as an indicator of faculty member interest in sustainability learning in engineering. 


\subsubsection{Development and Deployment of an Informal Student Survey}

An informal (i.e., not-validated) survey was developed and deployed to all undergraduate engineering students in December, 2014. The aim of the survey was to gather information from the students about their:

- $\quad$ comprehension of sustainability concepts acquired during their pre-university experiences;

- current comprehension of sustainability; and

- general attitudes towards sustainability - i.e. "what is one word you would use to describe sustainability"

Since half the first year cohort engages in a two-hour module on sustainability in September each year, first year students were asked whether or not they had taken the module or not. The deployment of the survey in December served to collect data that might indicate the influence of the two-hour module on student learning. This two-hour module is composed of approximately one and a half lectures of the first year engineering course (i.e.APSC 150: Case Studies in Engineering) that focused on sustainable development and engineering. While taking the course, their knowledge was assessed with a question on life cycle assessment in the final exam and an assignment on the Seven Questions to Sustainability (14).

\subsubsection{An Engineering for Sustainability Roundtable Discussion}

A two-hour roundtable discussion was convened in the fall of 2014 to gather ideas from interested faculty members from across the engineering disciplines about the sustainability knowledge, skills, and/or attitudes that a first year course could help students develop. The purpose of the roundtable was to develop a preliminary list of sustainability learning outcomes for the first year level to help students to develop their knowledge of sustainability.

\section{RESULTS AND DISCUSSION}

\subsection{Interest and Support for the Development of a Sustainability Learning Pathway}

The Dean and Associate Dean envision sustainability learning to be deeply integrated into all undergraduate engineering curricula. This format may be emerging as best practice (see the discussion). There were 39 undergraduate engineering courses that instructors self-identified as having sustainability content, addressing topics including environment, society, economy and technology, and sustainability focused (15).

\subsection{Development and Deployment of an Informal Student Survey}

107 first year students, approximately $13 \%$ of the first year cohort, responded to the survey. Of these, 49 had not yet taken APSC 150 and 58 had taken the sustainability module in APSC 150. In addition 105 respondents were from 4 th year engineering students.

The survey allowed for an overview of the current level of understanding of undergraduate engineering students on sustainability. One of the questions was "Please indicate how important you feel each of the following topics is to your interpretation of "sustainability". Some of the topics included: ecological resiliency, systems thinking, recycling, global and social justice, Life Cycle Analysis (LCA), distribution of wealth, Climate Change, etc. The students had to pick between critically important, very important, somewhat important, not at all important and unsure. LCA is one of the easier gateways for engineering students to grasp. In APSC 150, the concept is introduced, but the process is not reviewed nor did students actively engage in an LCA learning activity. However as shown in Figure 1, the importance of LCA, when considering sustainability, shifts to being more significant after taking the first year course. 


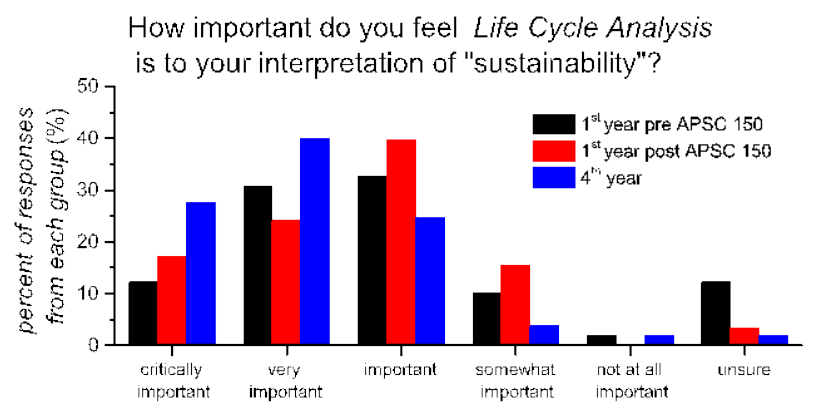

Figure 1: Survey results for the question: "how important you feel Life Cycle Analysis is to your interpretation of sustainability". $1^{\text {st }}$ year pre APSC 150 in black, $1^{\text {st }}$ year post APSC 150 course are in red.

On the other hand, $1^{\text {st }}$ year students prior to taking APSC 150 are more likely to associate sustainability with recycling, as in figure 2, and/or climate change, compared to other student groups. This is comparable to many results indicated in literature where concepts such as recycling get high scores in surveys due to having a high public profile and prominence in the media (11). In contrast, economical and social aspects of sustainability aren't covered as extensively in media, and if they aren't presented in the engineering curriclum there are high uncertainties in answers. For example, the survey results in figure 3 indicate that there was great uncertainty in students from all groups with the association of sustainability with geopolitics.

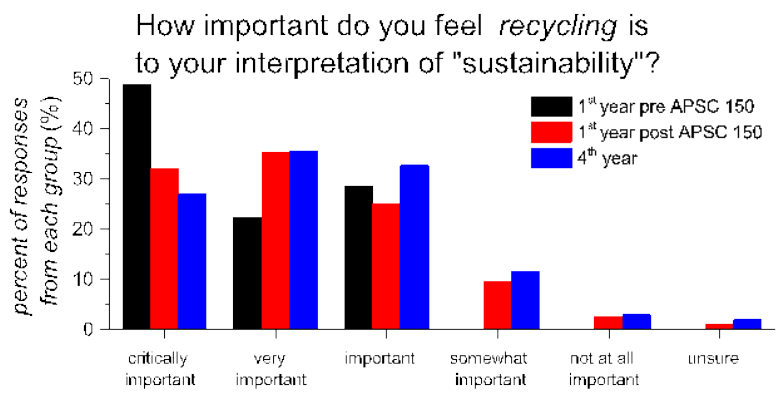

Figure 2: Survey results for the question: "how important you feel recycling is to your interpretation of sustainability". $1^{\text {st }}$ year pre APSC 150 in black, $1^{\text {st }}$ year post APSC 150 course are in red and $4^{\text {th }}$ year results are in blue

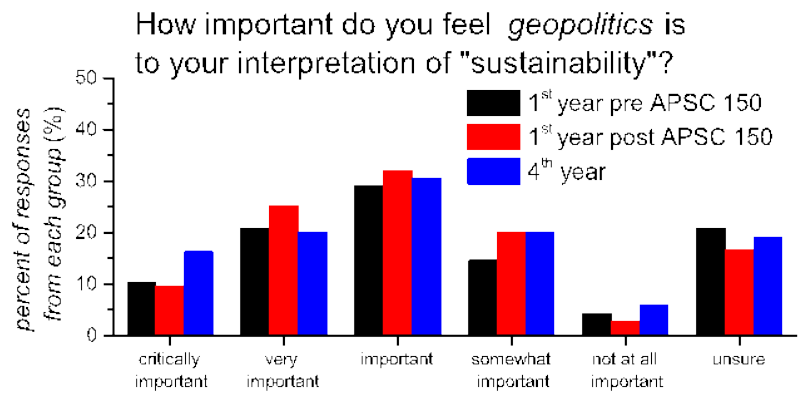

Figure 3: Survey results for the question: "how important you feel geopolitics is to your interpretation of sustainability". $1^{\text {st }}$ year pre APSC 150 in black, $1^{\text {st }}$ year post APSC 150 course are in red and $4^{\text {th }}$ year results are in blue

One concept that needs coverage and requires curriculum adjustment is systems thinking. Students responses vary, including great student uncertainty for systems thinking (Figure 4). Given the similar trend of distribution for $1^{\text {st }}$ and $4^{\text {th }}$ year student respondents, it is conceivable that systems thinking is not 
sufficiently addressed in the engineering curricula, despite it being one of the key competencies in sustainability development learning (16). These results closely mirror results found in the literature, where there is a great predominance in answers towards environmental aspects, but social and economic responses are deficient. (12)

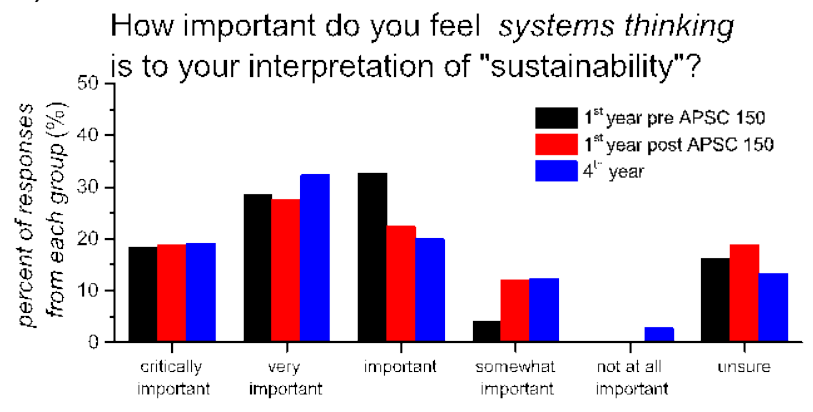

Figure 4: Survey results for the question: "how important you feel systems thinking is to your interpretation of sustainability". $1^{\text {st }}$ year pre APSC 150 in black, $1^{\text {st }}$ year post APSC 150 course.

The survey results indicate that some concepts of sustainability are present at an undergraduate level but that the curriculum should be redesigned to include more concepts in the social and economic pillars.

\subsection{An Engineering for Sustainability Roundtable Discussion}

There were 15 total attendees at the two-hour roundtable discussion during which the participants were able to begin developing a framework of intended learning outcomes and key themes related to sustainability for UBC engineering.

There were several suggestions on how to introduce sustainability all of which involved integrating sustainability throughout the curriculum. Examples included using case studies, in-class and out-of-class examples, and raising student awareness. Some possible first year learning outcomes that were presented are:

- Articulate the context of an engineering problem in terms of sustainability and identify areas of impact (including identifying all stakeholders);

- Describe the foundational concepts in sustainability (e.g. systems thinking) and demonstrate a working understanding of a sustainability lexicon; and

- Think critically to apply concepts from sustainability to real world problems; ask the right questions

One of the major themes that arose from the discussion was the need to prepare students for complexity.

\section{CONCLUSIONS AND NEXT STEPS}

Attitudinal barriers to embedding sustainability into engineering curricula at UBC appear largely absent. Indeed, the work presented in this paper suggests that there is significant interest on the part of administrators, faculty members and students to "get on with it." The need for understanding the theory and practice of engineering-for-sustainability seems obvious.

In addition to establishing the "student will" to engage in learning engineering for sustainability, the survey data described here provide an informal indication of first year student understanding of sustainability and provide the authors with gaps and misconceptions regarding sustainability. They also provide benchmarking data that may be used informally to signal the effects of subsequent changes to the first year program. Gaps suggested by the survey data and the results of the faculty roundtable discussion include understanding the notion of complexity as manifested by systems thinking as well as thinking at different scales (from societal to detailed analysis). Misconceptions include the notion that sustainability relates only or primarily to environmental issues. Further, survey data suggest that pedagogies deployed at the first year level should support each student personalizing the issues of engineering-for- 
sustainability, such that sustainability is viewed as having links to behaviour as well as engineering projects, thus sowing the seeds for future understanding of the connections between the built environment and issues of "behavioural lock-in."

The next steps for the APSC SLP initiative involve creating a framework of learning outcomes, activities, and assessments aimed at filling sustainability knowledge gaps, and addressing first year student misconceptions about engineering and sustainability. In these tasks, the literature offers significant guidance (e.g., Jowitt (17); Blizzard (18); Mulder (19)). Once created, the authors intend to pilot the framework, with subsequent adjustments made that are based on pre- and post-course student data and possibly focus group data collected during the piloting stage.

\section{Acknowledgements}

The authors would like to thank the Teaching and Learning office of the UBC Sustainability Initiative and the office of the Dean of Applied Science at UBC for supporting the development of an APSC Sustainability Learning Pathway Initiative

\section{References}

(1) USI Attributes http://sustain.ubc.ca/courses-teaching/sustainability-attributes

(2) http://sustain.ubc.ca/courses-teaching

(3) Engineers Canada / Ingénieurs Canada, Canadian Engineering Accreditation Board: Accreditation Criteria and Procedures / Bureau canadien d'agrément des programmes de génie: Normes et procédures d'agrément, 2008. (Latest edition:

http://www.engineerscanada.ca/e/files/Accreditation Criteria Procedures 2009.pdf)

(4) http://egad.engineering.queensu.ca/

(5) UBC seeds; http://sustain.ubc.ca/courses-teaching/seeds

(6) Greenest City Action Plan; http://sustain.ubc.ca/get-involved/students/greenest-city-scholars

(7) USI Spot Light; http://sustain.ubc.ca/courses-teaching/support-educators/spotlight-program

(8) USI teaching fellows; http://sustain.ubc.ca/courses-teaching/teaching-learning-fellowships

(9) Carew, A. L.; Mitchell, C. A. 2002. Characterizing Undergraduate Engineering Students' understanding of Sustainability. Eur.J. Eng. Ed, 27(4): 349-361

(10) Azapagic, A., Perdan, S. and Shallcross, D. 2005. How much do engineering students know about sustainable development? The findings of an international survey and possible iplications for the engineering curriculum. Eur.J. Eng. Ed, 30(1): 1-19

(11) Nicolaou, I.; Conlon, 2012. What do final year engineering students know about sustainable development. E. Eur.J. Eng. Ed, 37, 267-277.

(12) Hanning, A.; Priem Abelsson, A.; Lundqvist, U.; Svanström, M. 2012. Are we educating engineers for sustainability. Int $J$ of Sus in Higher Ed. 13, 305-320.

(13) Burian, S. 2010. Teaching Sustainability and Sustainable Engineering Practice in the Civil Engineering Curriculum. Proc. American Society for Engineering Education Annual Caonf. And Exposition, American Society for Engineering Education, Louisville, KY

(14) Mining, M. 2002. Seven Questions to Sustainability: How to Assess the Contribution of Mining and Minerals Activities." IISD. Sustainable Development (MMSD) North America

(15) http://sustain.ubc.ca/courses-teaching/courses (accessed date: October 2014)

(16) Weik, A.; Withycombe, L.; Redman, C.L. 2011. Key competencies in sustainability: a reference framework for academic program development. Sustain Sci 6, 203-218.

(17) Jowitt, P. 2004, Systems and sustainability: sustainable development and civil engineering education, Engineering Sustainability,157(ES2)

(18)Blizzard, J. 2012. A framework for sustainable whole systems design. Design Studies. 33(5):456-479

(19)Mulder, K.; Segalas, J.; Ferrer-Balas, D. 2012. How to educate engineering for sustainable development: Ten years of discussion, remaining challenges. International Journal of Sustainability in Higher Education. 13(3): 211-218 